\title{
Evidence-based adviezen voor begrijpelijk schrijven, een utopie?
}

Jacqueline Evers-Vermeul en Carla van Rooijen

TT 39 (2): 231-244

DOI: 10.5117/TVT2017.2.EVER

\begin{abstract}
Evidence-based advice for comprehensible writing, a daydream?

Organizations and writers striving to use plain language could benefit from evidence-based pieces of writing advice. At present, recommendations for producing comprehensible texts are often based on experience with the target group and/or common-sense logic, while previous effect studies have shown that applying such recommendations does not necessarily improve texts. In this paper we show the complexity of translating research results into evidence-based advice for comprehensible writing by discussing three dilemmas. First, we discuss the selection of a reliable evidence base, with a focus on the selection of measures that objectively reflect comprehension. Second, we discuss the generalizability of research results to types of texts, tasks, modalities, and readers other than the ones actually studied. Third, we address the complexity of turning conflicting results and subtle interaction effects into valid and nuanced but still comprehensible and applicable recommendations. We will argue that, due to its complexity, this 'translation' needs to be made by linguists instead of laymen.
\end{abstract}

Keywords: comprehensibility, evidence-based writing, readability, writing advice

\section{$1 \quad$ Inleiding ${ }^{1}$}

In Nederland zijn 1,3 miljoen Nederlanders tussen de 16 en 65 jaar laaggeletterd (Stichting Lezen en Schrijven, 2017), evenals 17,9 procent van de vijftienjarigen (PISA-2015-resultaten, samengevat in Feskens, Kuhlemeier, \& Limpens, 2016). Bedrijven, overheidsinstanties en educatieve uitgevers 
doen daarom moeite begrijpelijke teksten te produceren, soms met ondersteuning van commerciële taalbureaus of non-profitorganisaties zoals Stichting Makkelijk Lezen. Bij gebrek aan een algemene Schrijfwijzer Begrijpelijke Taal hanteren deze organisaties elk hun eigen set schrijfadviezen, ontwikkeld op basis van talige intuïties, kleinschalige tests, of jarenlange praktijkervaring met zwakke lezers. Deze adviezen zijn echter niet wetenschappelijk gevalideerd.

Vanwege de behoefte aan richtlijnen circuleren er inmiddels allerlei aannemelijk klinkende adviezen, zoals 'maak korte zinnen' en 'vermijd samengestelde zinnen', en wordt er gebruikgemaakt van leesbaarheidsformules. Dit leidt er bijvoorbeeld toe dat schrijvers samengestelde zinnen opknippen en signaalwoorden zoals daarom en bovendien achterwege laten. Land, Van Silfhout en collega's hebben echter aangetoond dat het weglaten van signaalwoorden een negatief effect heeft op het tekstbegrip van zwakke (en sterke) lezers (Land, 2009; Land, Sanders, \& Van den Bergh, 2008; Van Silfhout, Evers-Vermeul, \& Sanders, 2015). Wetenschappelijke validering van de gehanteerde criteria is daarom gewenst, zoals Van Silfhout, Evers-Vermeul en Sanders (2013) betogen en zoals beoogd werd met het NWO-themaprogramma Begrijpelijke Taal (Sanders \& Jansen, 2011).

Met de Kennisbank Begrijpelijke Taal (Pander Maat \& Lentz, 2011) is een grote stap in de richting van evidence-based schrijfadviezen gezet. Deze Kennisbank brengt het begrijpelijkheidsonderzoek in kaart en werkt drempelverlagend doordat gebruikers niet meer zelf verschillende databases en niet-relevante publicaties hoeven te doorzoeken. Hiermee kunnen geïnteresseerden makkelijker zelf nagaan in hoeverre adviezen over begrijpelijk schrijven wetenschappelijk bezien hout snijden. Ook faciliteert de Kennisbank het schrijven van overzichtsartikelen en meta-analyses over effecten van specifieke tekstkenmerken (Van Hooijdonk \& Spooren, 2011; Koops van 't Jagt, Hoeks, Jansen, De Winter, \& Reijneveld, 2015).

Ondanks de Kennisbank is de vertaalslag van wetenschappelijke bevindingen naar concrete evidence-based schrijfadviezen complex. In dit artikel bespreken we drie dilemma's die zich voordoen als je een schrijfadviesbank wilt ontwikkelen: welke begripsmaten kies je als evidence base (paragraaf 2), in hoeverre kun je bevindingen generaliseren (paragraaf 3), en hoe kom je tot begrijpelijke en toepasbare adviezen (paragraaf 4)? Elk dilemma illustreren we met voorbeelden uit een Alfa-Meerwaardeproject van de Universiteit Utrecht in samenwerking met Stichting Makkelijk Lezen, waarin een eerste aanzet tot zo'n schrijfadviesbank is gedaan (zie www.schrijfadviezen.net). 


\section{$2 \quad$ Welke begripsmaten kies je als evidence base?}

Effecten van tekstkenmerken kunnen op allerlei manieren vastgesteld worden: met tekstbegripvragen, lees- en reactietijden, snelheid en accuraatheid waarmee lezers taken uitvoeren, en bijvoorbeeld tekstwaarderingsvragen. Ontwikkelaars van een schrijfadviesbank staan dan ook meteen voor de keuze welke begripsmaten zij selecteren als evidence base. Hoe begrijpelijk een tekst is, kan blijken uit het leesproduct (wat moeten lezers met de tekst kunnen? - zie paragraaf 2.1) en het leesproces (hoe gemakkelijk komt dat product tot stand? - zie paragraaf 2.2).

Naast de keuze voor begripsmaten zijn enkele algemene selectiecriteria van belang, zoals de eis dat er alleen wetenschappelijke studies in de evidence base komen die effecten van individuele tekstkenmerken objectief en met statistische toetsing vaststellen. Artikelen met louter theorievorming of enkel kwalitatieve of anekdotische observaties blijven dan buiten beschouwing, evenals studies waarin de effecten van verschillende tekstkenmerken niet te onderscheiden zijn. Een kwaliteitscontrole is eveneens gewenst, zodat onderzoeken met duidelijke validiteitsproblemen bij voorbaat kunnen worden uitgesloten, evenals studies waarbij de rapportage zo summier is dat niet te achterhalen valt hoe tekstkenmerken gemanipuleerd zijn of wat precies de afhankelijke variabelen zijn.

\subsection{Productmaten}

Veel informatieve teksten worden gelezen om kennis te vergaren (readingto-learn, Sticht, 1985), zoals bijvoorbeeld onderwijsteksten. Hierbij ligt het voor de hand om effecten van tekstkenmerken te achterhalen via offline indicatoren van tekstbegrip, zoals scores die proefpersonen halen door de beantwoording van open vragen, meerkeuzevragen en andere soorten gesloten vragen over de inhoud van de tekst, het invullen van cloze-testen, en het schrijven van samenvattingen en parafrases. Ook het onthouden van informatie veronderstelt dat lezers deze begrepen hebben - zelfs al gebeurt dat in termen van Kintsch (1988) slechts op het niveau van de surface code. Het lijkt daarom logisch om onthoudbaarheids- of recall-maten, zoals vrije en gestuurde reproductie, eveneens onderdeel te laten vormen van de evidence base.

Teksten worden echter voor allerlei doelen gelezen (Sticht, 1985): teksten uit het gezondheidsdomein zijn bedoeld om symptomen van bepaalde aandoeningen te achterhalen (reading-to-learn), te weten hoe je een medicijn moet innemen (reading-to-do), of te beslissen of je een medicijn moet innemen (reading-to-decide; Van Hooijdonk \& Spooren, 2011), en 
handleidingen bij apparaten zijn vooral bedoeld om bepaalde acties te kunnen uitvoeren (reading-to-do). Voor instructieve genres is het daarom wenselijk de kwaliteit van taakuitvoering als afhankelijke maat in de evidence base te accepteren, en ook de vindbaarheid van informatie, zoals bij gemeentelijke websites of medicinale bijsluiters (Lentz \& Pander Maat, 2010).

De inperking van de evidence base tot objectieve maten houdt in dat subjectieve maten, zoals het door lezers ervaren tekstbegrip, buiten beschouwing blijven. Dergelijke maten kunnen weliswaar relevant zijn voor schrijvers (bijvoorbeeld om effecten op imago te achterhalen), maar geven vooral een indicatie van tekstwaardering, en niet per se van begrip.

\section{$2.2 \quad$ Procesmaten}

Begrip is iets wat al lezend en met meer of minder moeite tot stand komt. Leesprocesmaten zouden daarom eveneens onderdeel van de evidence base moeten zijn. Hierbij valt te denken aan online tekstbegripmaten zoals leessnelheid, snelheid van de taakuitvoering en reactietijden op secundaire taken, waarbij de veronderstelling is dat moeilijkere teksten vanwege grotere cognitieve belasting van het werkgeheugen leiden tot vertraging.

Studies die achterhalen welke hersengebieden door bepaalde tekstkenmerken geactiveerd worden (fMRI-studies) zouden we voorlopig van de evidence base willen uitsluiten. Bevindingen daaruit betreffen weliswaar objectieve maten, maar deze zijn vooralsnog moeilijk te interpreteren in termen van mate van begrip.

Een tekstkenmerk waarbij leesprocesmaten erg relevant zijn, zo bleek in het Alfa-Meerwaardeproject, zijn negaties. Syntactische negaties (woorden als niet en geen) en morfologische negaties (prefixen zoals on- en in-) zijn onderzocht in de veronderstelling dat ze begripsproblemen zouden opleveren, maar in meerdere studies vond men minimale of zelfs helemaal geen effecten op offline begripsmaten (Burgers, Beukeboom, Sparks, \& Diepeveen, 2015; Margolin, 2013; Margolin \& Abrams, 2009). Allerlei studies naar het verwerkingsgemak van negaties wijzen echter uit dat negaties onder bepaalde condities de lezer vertragen (Kaup, Lüdtke, \& Zwaan, 2005; Lüdtke \& Kaup, 2006; Paradis \& Willners, 2006; Sherman, 1973, 1976). Het negeren van deze leesprocesresultaten en daarmee 'begrijpelijk' verklaren van negaties op basis van louter offline begripsmaten zou geen recht doen aan het feit dat lezers blijkbaar toch moeite hebben met het verwerken van zinnen met negaties. ${ }^{2}$ 


\section{$3 \quad$ In hoeverre kun je bevindingen generaliseren?}

Is de evidence base afgebakend aan de hand van criteria zoals die in paragraaf 2, dan moet de reikwijdte van het advies bepaald worden. Deze hangt af van de generaliseerbaarheid van bevindingen en dus van factoren zoals type lezers onder wie en de modaliteit waarin de onderbouwende studies zijn uitgevoerd. Een eerste optie hierbij is om de reikwijdte van het advies expliciet in te perken, zoals we in het Alfa-Meerwaardeproject gedaan hebben bij adviezen over lettertype en -grootte, regellengte en regelafstand. In bijna alle studies over deze onderwerpen lazen de proefpersonen van een beeldscherm. Omdat factoren als schermresolutie hier van invloed kunnen zijn, hebben wij bij deze adviezen aangegeven dat ze niet zonder meer van toepassing zijn op papieren teksten.

Zouden we deze werkwijze volgen voor alle variabelen die de generaliseerbaarheid kunnen beïnvloeden, dan blijft een schrijfadviesbank met enige reikwijdte slechts toekomstmuziek. Er zijn immers altijd wel andere onderwerpen, tekstsoorten, taken of typen proefpersonen denkbaar waarop nog niet is getest. Een werkhypothese kan daarom zijn dat - zodra meerdere studies eenzelfde richting op wijzen - resultaten gegeneraliseerd kunnen worden naar andere teksten, proefpersonen en dergelijke totdat het tegendeel empirisch bewezen is. Bijvoorbeeld: een advies gebaseerd op vergelijkbare resultaten uit meerdere effectstudies met informatieve teksten geldt ook voor instructieve en argumentatieve teksten. Het inperken van het advies naar specifieke tekstsoorten gebeurt dan alleen als blijkt dat het betreffende tekstkenmerk bij bijvoorbeeld argumentatieve teksten een averechts in plaats van een gunstig effect heeft op tekstbegrip. In paragraaf 3.1-3.3 bespreken we drie factoren waarbij een grote kans bestaat dat de werkhypothese in het gedrang komt: de omvang van de evidence base, de taal en het type lezers.

\subsection{Omvang van de evidence base}

Voor tekstkenmerken die niet experimenteel onderzocht zijn, is een empirisch gevalideerd advies onmogelijk. Voor sommige tekstkenmerken bestaat de evidence base daarentegen uit slechts één of enkele onderzoeken. De opsteller van evidence-based schrijfadviezen staat dan voor een dilemma: wel of geen advies formuleren?

Conclusies trekken uit één enkele studie lijkt af te raden, zeker als daarin sprake is van een single-message design, waarbij effecten van tekstkenmerken getest zijn op basis van experimentele varianten van één tekst. Dit onderzoeksontwerp staat ter discussie, juist vanwege de generaliseer- 
baarheid van de bevindingen, en er wordt daarom gepleit voor multiplemessage designs, replicatieonderzoek en meta-analyses (Meuffels \& Van den Bergh, 2005; O'Keefe, 2002; Open Science Collaboration, 2015). Om de lat niet te hoog te leggen, bepleiten wij dat twee of drie studies met vergelijkbare resultaten en operationalisatie van het tekstkenmerk al voldoende kunnen zijn voor het opstellen van een schrijfadvies.

In het Alfa-Meerwaardeproject deed dit dilemma zich voor bij het schrijfadvies over typografische markeringen, bedoeld om specifieke details in teksten te benadrukken. Hiervoor konden wij slechts twee onderbouwende studies vinden: Golding en Fowler (1992) en Lorch, Lorch en Klusewitz (1995). Deze studies overlappen elkaar op belangrijke vlakken: ze gebruiken onderstrepingen als markering, testen op recall met open vragen, en concluderen dat markeringen helpen details te onthouden, zonder de recall van ongemarkeerde informatie te hinderen. Daarmee vormen deze studies de basis voor een bescheiden eerste leidraad: 'Gebruik markeringen voor details in de tekst die de lezer moet onthouden. Over de effecten van verschillende typen markering (onderstreping, cursivering, vet drukken of hoofdlettergebruik) is weinig bekend. Wel weten we dat het geen verschil maakt of je onderstreept of hoofdletters gebruikt (Lorch et al., 1995).'

\subsection{Taal}

Het gros van het experimentele begrijpelijkheidsonderzoek is uitgevoerd onder Engelstalige proefpersonen. Daarmee staan ontwerpers van een schrijfadviesbank opnieuw voor een dilemma: kunnen dergelijke resultaten dienen als evidence base voor Nederlandse schrijfadviezen? Wij pleiten ervoor dat het antwoord 'ja' is, gezien de vele overeenkomsten tussen de talen. Dit antwoord gaat alleen niet op wanneer de talen juist op het onderzochte talige kenmerk cruciaal van elkaar verschillen, zoals de plaatsing van werkwoorden in de zin.

Een voorbeeld hiervan betreft de verwerking van relatieve bijzinnen. Gordon, Randall en Levine (2002) tonen aan dat Engelse objectrelatieve bijzinnen zoals (1) langzamer verwerkt en slechter onthouden worden dan subjectrelatieve bijzinnen zoals (2). Dit concrete resultaat kan moeilijk dienen als evidence base voor een schrijfadvies voor Nederlandse teksten, aangezien de Nederlandse tegenhanger van beide zinnen, zin (3), dezelfde is.

(1) It was the dancer that the fireman liked before the argument began.

(2) It was the dancer that liked the fireman before the argument began.

(3) Het was de danser die de brandweerman leuk vond voordat de ruzie begon. 
Een vergelijkbare situatie doet zich voor met een Engelstalige studie naar het invoegen van koppeltekens om ambiguïteit te vermijden. Anema en Obler (2012) laten zien dat Engelse lezers de tweede helft van zinnen als (4) sneller verwerken wanneer een koppelteken de ambiguïteit van little used car ('weinig gebruikte auto' vs. 'kleine gebruikte auto') weghaalt, zoals in (5).

(4) He drove the little used car to Chicago.

'Hij reed de kleine gebruikte auto naar Chicago.'

(5) He drove the little-used car to Chicago.

'Hij reed de weinig gebruikte auto naar Chicago.'

Omdat in de Nederlandse variant van deze zin niet koppeltekens maar spaties of komma's ambiguïteit voorkomen (vergelijk [6] en [7] enerzijds en [8] en [9] anderzijds), laten de data van Anema en Obler (2012) zich niet goed vertalen naar de Nederlandse situatie. Effecten van spaties en komma's waren niet het onderwerp van het Engelstalige onderzoek en zouden dus in nieuwe studies met Nederlandse proefpersonen onderzocht moeten worden.

(6) Hij reed in de laatst gebruikte auto naar Chicago.

(7) Hij reed in de laatstgebruikte auto naar Chicago.

(8) Zij woont in een heerlijk groot huis.

(9) Zij woont in een heerlijk, groot huis.

\subsection{Type lezer}

Het generaliseerbaarheidsdilemma treedt ook op bij lezerskenmerken. Vanwege hun toegankelijkheid is veel onderzoek uitgevoerd onder hoogopgeleide studenten, maar het zou jammer zijn als we alleen voor hen schrijfadviezen zouden hebben. Gelukkig lijkt de werkhypothese uit de inleiding van paragraaf 3 (resultaten zijn generaliseerbaar totdat het tegendeel bewezen is) ook hier een redelijke keuze: als sterke lezers minder snel leesproblemen ervaren dan zwakke lezers, maar desondanks blijken te profiteren van tekstuele ingrepen, dan is de kans groot dat zwakke lezers dit eveneens doen.

Juist bij deze generaliseerbaarheidsfactor is echter ook voorzichtigheid geboden; sterke lezers reageren soms anders op tekstuele wijzigingen dan zwakke lezers. Ze profiteren soms niet van een tekstuele verandering waar zwakke lezers dat wel doen, of profiteren juist veel meer dan zwakke lezers. In zo'n geval kan het wijs zijn om toch expliciet vermelden op welk lezerstype de onderliggende onderzoeken zich hebben gericht. Zo 
onderzochten Shapiro en Milkes (2004) welk type verwijzing naar personen zorgde voor beter tekstbegrip: een persoonlijk voornaamwoord of herhaling van de eigennaam van die persoon. Het type verwijzing maakte voor zwakkere en middelmatige lezers geen verschil, maar sterkere lezers ondervonden hinder wanneer namen werden herhaald (de zogenoemde repeated-name penalty). Vormden de resultaten van de sterke lezers de enige evidence base, dan zouden deze vertaald kunnen worden naar het advies: 'Verwijs vooral met persoonlijke voornaamwoorden en minder met eigennamen naar personen die je eerder in je tekst genoemd hebt.' Dit advies zou in de praktijk echter alleen het tekstbegrip van sterke lezers bevorderen. Er treedt dan een 'Mattheüseffect' op, waarbij de kloof tussen sterke en zwakke lezers vergroot wordt (Rigney, 2010). Zoals Lentz, Herijgers, Nell, Sikkema en Pander Maat elders in dit themanummer bepleiten, zouden adviezen voor begrijpelijk schrijven juist een - zoals zij dat noemen 'Martinuseffect' moeten bewerkstelligen: een effect dat de rol van leesvaardigheid verkleint.

Naast leesvaardigheid kunnen lezerskenmerken zoals leeftijd, geslacht, mate van voorkennis, opleidingsniveau, werkgeheugencapaciteit en algemene taalvaardigheid een rol spelen in de totstandkoming van tekstbegrip. McNamara en Kintsch (1996) tonen bijvoorbeeld een reverse cohesion effect aan, waarbij lezers met weinig voorkennis profiteren van de toevoeging van coherentiemarkeerders, terwijl lezers met veel voorkennis juist baat hebben bij een minder cohesieve tekst. ${ }^{3}$ Daarnaast laten Wilson en Park (2008) leeftijdseffecten zien: ouderen van rond de zeventig hebben bij het onthouden van gezondheidsadviezen zoals 'Neem dit medicijn niet voor het eten in' meer last van negaties dan studenten.

\section{$4 \quad$ Hoe kom je tot begrijpelijke en toepasbare adviezen?}

Als de reikwijdte van bevindingen is bepaald, kunnen de daadwerkelijke evidence-based schrijfadviezen geformuleerd worden. Bij deze vertaalslag spelen dilemma's rondom onderzoeken met tegenstrijdige resultaten (zie paragraaf 4.1) en complexe interactie-effecten (zie paragraaf 4.2), en kan juist een solide evidence base de begrijpelijkheid van adviezen en daarmee de toepasbaarheid ervan door leken in de weg staan. Tegenstrijdige resultaten en interactie-effecten laten zich immers niet makkelijk omzetten in een eenduidig advies als 'vermijd negaties', simpelweg omdat de realiteit ingewikkeld in elkaar steekt. 


\subsection{Omgaan met tegenstrijdige resultaten}

Studies naar eenzelfde tekstkenmerk leveren niet altijd vergelijkbare resultaten op. Het is lastig om op basis van zulke resultaten een eenduidig schrijfadvies te formuleren. Het negeren van studies met afwijkende resultaten is uiteraard geen optie, zeker wanneer enkel studies met voldoende kwaliteit opgenomen zijn in de evidence base: gebrekkige validiteit kan dan niet meer als verklaring - of excuus - worden gebruikt voor de afwijkende resultaten.

In het Alfa-Meerwaardeproject waren verschillen in uitkomsten herhaaldelijk te herleiden tot interactie-effecten met andere factoren die in de ene studie niet en in de andere studie wel waren meegenomen, variatie in de manier waarop stimuli gemanipuleerd zijn en/of de gekozen begripsmaat. Uit effectstudies naar het toevoegen van connectieven zoals want en daarna blijkt bijvoorbeeld dat deze heel duidelijk het leesproces beïnvloeden en het begrip van lokale coherentie vergroten (Van Silfhout, EversVermeul, Mak, \& Sanders, 2014), maar dat ze niet altijd leiden tot een betere recall (Sanders \& Noordman, 2000) of hogere scores op vragen die globaal tekstbegrip meten (Van Silfhout, 2014). Het interpreteren van dit soort (vaak subtiele) verschillen in uitkomsten kan leiden tot de conclusie dat studies elkaar niet geheel tegenspreken, maar wel nuanceren. In dat geval kan er alsnog een advies ontstaan, zij het genuanceerder en hierdoor vaak ingewikkelder (zie paragraaf 4.2 voor een voorbeeld). Deze stap in het vertaalproces vereist dan ook communicatiekundige en statistische bagage.

Is de tegenstrijdigheid in resultaten niet te verklaren, dan zal de opsteller van schrijfadviezen moeten accepteren dat er geen eenduidig advies mogelijk is. Wel kan het in zo'n geval z zijn om deze conclusie te rapporteren: organisaties en individuele schrijvers kunnen er dan voor kiezen hun aandacht te verleggen naar tekstkenmerken die de begrijpelijkheid van hun teksten wél eenduidig ten goede komen.

\subsection{Omgaan met interactie-effecten}

Het formuleren van evidence-based adviezen die ook voor leken begrijpelijk en bruikbaar zijn is lastig als de evidence base bestaat uit complexe interactie-effecten. We illustreren de complexiteit van dit vertaalproces met het eerder genoemde tekstkenmerk 'verwijzing naar personen'. In studies naar het onderscheid tussen verwijzing met persoonlijke voornaamwoorden dan wel eigennamen komen (interactie-effecten tussen) variabelen aan bod die vakkennis vereisen, zoals grammaticale rollen, thematische rollen, topicalisatie, ambiguïteit en focusverschuiving (Arnold, Eisen- 
band, Brown-Schmidt, \& Trueswell, 2000; Chambers \& Smyth, 1998; Cinkara \& Cabaroğlu, 2015; Gordon \& Chan, 1995; Gordon, Grosz, \& Gilliom, 1993; Shapiro \& Milkes, 2004).

De meest geteste variabele in deze studies is de verdeling van grammaticale rollen (subject/direct object) over verwijswoord en antecedent. Uit meerdere studies blijkt dat verwijzingen in de vorm van herhaalde namen trager worden verwerkt dan persoonlijke voornaamwoorden wanneer zowel verwijswoord als antecedent het grammaticaal subject zijn in hun respectievelijke zinnen (Chambers \& Smyth, 1998; Cinkara \& Cabaroğlu, 2015; Gordon, Camblin, \& Swaab, 2004; Gordon \& Chan, 1995; Gordon et al., 1993; Shapiro \& Milkes, 2004). Aannemende dat schrijvers in staat zijn het onderwerp van een zin te herkennen, kan dit resultaat opgenomen worden in een advies over verwijzing naar personen: 'Herhaal altijd de naam als een verwijzing dubbelzinnig is. Dit gebeurt bijvoorbeeld als de tekst gaat over twee personen van hetzelfde geslacht. Gebruik een verwijswoord als de persoon het onderwerp is, en ook het onderwerp van de voorgaande zin was' (vergelijk het advies op www.schrijfadviezen.net).

Andere variabelen in onderzoek naar verwijzingen zijn de thematische rol van verwijswoorden (agens/thema) en hun positie in de zin (wel/niet getopicaliseerd). Deze variabelen blijken niet te interacteren met het type verwijzing (Gordon \& Chan, 1995; Gordon et al., 1993), wat in het advies verwerkt kan worden door te vermelden dat de variabelen niet van belang zijn, bijvoorbeeld: 'Hierbij is het niet van belang op welke plek de verwijzing zelf staat.' Hiermee wordt het advies immers niet ingewikkelder, maar wel vollediger.

Soms weegt de mate waarin variabelen een advies compliceren zwaarder dan de mogelijke winst in begrijpelijkheid die een uitgebreider advies oplevert. Gordon en Chan (1995) onderzochten bijvoorbeeld verwijzingen in constructies zoals (10), waarbij het verwijswoord de actor is in een passieve zin.

(10) Suzan besloot Fred een hamster te geven. Ze werd eindeloos uitgehoord door hem/Fred over de verzorging van het beestje.

Er blijkt in zinnen als (10) geen repeated name penalty op te treden, maar uitbreiding van het advies op basis van dit resultaat zouden we afraden, omdat termen als 'passiviteit' en 'actor' het advies veel ingewikkelder zouden maken. Een algemene richtlijn voor het nemen van dit soort beslissingen is lastig te geven, maar die zou wellicht kunnen worden geformuleerd aan de hand van nader onderzoek naar de toepasbaarheid van evidence- 
based schrijfadviezen door tekstwetenschappelijke leken. Tot die tijd kunnen schrijvers wel al geholpen worden door bij het advies heldere voorbeelden te geven en de wetenschappelijke onderbouwing uitgebreid toe te lichten.

\section{$5 \quad$ Conclusie}

Evidence-based schrijfadviezen formuleren is geen sinecure, zelfs als er consensus is over de selectie van product- en procesmaten die dienen als objectieve operationalisaties van de notie tekstbegrip. Toch denken we dat dergelijke adviezen geen utopie zijn, zolang we accepteren dat we zullen moeten werken vanuit de hypothese dat resultaten, zodra meerdere studies eenzelfde richting op wijzen, gegeneraliseerd kunnen worden naar andere tekstsoorten, taken, talen, modaliteiten of lezerstypen totdat het tegendeel empirisch bewezen is. Deze werkhypothese lijkt ons een beter alternatief dan helemaal geen evidence-based adviezen opstellen en schrijvers laten terugvallen op niet-gevalideerde adviezen.

Tegelijkertijd zien we dat de hoeveelheid effectstudies voor veel tekstkenmerken nog vrij mager is. Graag roepen we tekstwetenschappers op om de effecten van tekstkenmerken te blijven onderzoeken, en dan juist bij zwakke lezers, de groep die het meest zou moeten profiteren van begrijpelijke teksten. Een minimaal alternatief is dat er in die effectstudies op zijn minst gecontroleerd wordt voor leesvaardigheid en eventueel ook voor andere lezerskenmerken. Een betere optie is dat lezerskenmerken worden meegenomen als verklarende variabele. Lentz en collega's (dit themanummer) illustreren hoe dit kan leiden tot genuanceerde inzichten.

De vertaalslag van onderzoeksresultaten naar adviezen blijkt complex. Dit roept de vraag op wie deze vertaalslag het best kan maken. Gezien de expertise die nodig is om wetenschappelijke terminologie te doorgronden, operationalisaties te vergelijken en statistische uitkomsten en tekstuele manipulaties op waarde te schatten, zijn wij van mening dat de verantwoordelijkheid hiervoor bij wetenschappers moet liggen. Dit kan niet zonder verdere subsidiëring van deze uitdagende, maar tijdrovende taak. We hopen dan ook dat begrijpelijk schrijven met initiatieven als het NWOprogramma Begrijpelijke Taal hoger op de wetenschappelijke agenda is gekomen en dat wij met ons Alfa-Meerwaardeproject een basis hebben gelegd voor een groeiende verzameling toepasbare evidence-based schrijfadviezen. 


\section{Noten}

1. Dit artikel is mede mogelijk gemaakt door een NWO-Alfa-Meerwaardesubsidie toegekend aan de eerste auteur.

2. Tekstkenmerken die het leesproces vertragen, vormen op zich geen probleem. Sommige concepten zijn immers simpelweg complexer dan andere. De vraag is echter of er alternatieve manieren zijn om dezelfde boodschap over te dragen zonder dat zo'n vertraging optreedt.

3. O'Reilly en McNamara (2007) laten zelfs een nog genuanceerder beeld van de interactie tussen voorkennis, leesvaardigheid en mate van coherentie zien.

\section{Bibliografie}

Anema, I., \& Obler, L.K. (2012). Hyphens for disambiguating phrases: Effectiveness for young and older adults. Reading and Writing, 25(9), 2091-2106.

Arnold, J.E., Eisenband, J.G., Brown-Schmidt, S., \& Trueswell, J.C. (2000). The rapid use of gender information: Evidence of the time course of pronoun resolution from eyetracking. Cognition, $76(1), \mathrm{B}_{3}-\mathrm{B} 26$.

Burgers, C., Beukeboom, C.J., Sparks, L., \& Diepeveen, V. (2015). How (not) to inform patients about drug use: Use and effects of negations in Dutch patient information leaflets. Pharmacoepidemiology and Drug Safety, 24(2), 137-143.

Chambers, C.G., \& Smyth, R. (1998). Structural parallelism and discourse coherence: A test of centering theory. Journal of Memory and Language, 39(4), 593-608.

Cinkara, E., \& Cabaroğlu, N. (2015). Parallel functioning hypothesis to explain pronoun resolution and processing load: Evidence from eye-tracking. Journal of Quantitative Linguistics, 22(2), 119-134.

Feskens, R., Kuhlemeier, H., \& Limpens, G. (2016). Resultaten PISA-2015 in vogelvlucht: Praktische kennis en vaardigheden van 15-jarigen. Arnhem: Cito. Geraadpleegd op 28 februari 2017: http://www.cito.nl/onderzoek\%2oen\%2owetenschap/deelname_int_onderzoek/pisa/actueel.

Golding, J.M., \& Fowler, S.B. (1992). The limited facilitative effect of typographical signals. Contemporary Educational Psychology, 17(2), 99-113.

Gordon, P.C., \& Chan, D. (1995). Pronouns, passives, and discourse coherence. Journal of Memory and Language, 34(2), 216-231.

Gordon, P.C., Camblin, C.C., \& Swaab, T.Y. (2004). On-line measures of coreferential processing. In M. Carreiras \& C.Jr. Clifton (Red.), The on-line study of sentence comprehension: Eyetracking, ERPs, and beyond (pp. 139-150). Hove, UK: Psychology Press.

Gordon, P.C., Grosz, B.J., \& Gilliom, L.A. (1993). Pronouns, names, and the centering of attention in discourse. Cognitive Science, $17(3)$, 311-347.

Gordon, P.C., Randall, H., Levine, W.H. (2002). Memory-load interference in syntactic processing. Psychological Science, 13(5), 425-430.

Hooijdonk, C. van, \& Spooren, W. (2011). De rol van beeld in tekstverwerking: Een overzicht van bestaand onderzoek. Tïdschrift voor Taalbeheersing, 33(3), 233-248.

Inspectie van het Onderwijs (2013). De staat van het onderwijs: Onderwijsverslag 2011-2012. Den Haag: Mediagroep Den Haag.

Kaup, B., Lüdtke, J., \& Zwaan, R.A. (2005). Effects of negation, truth value, and delay on picture 
recognition after reading affirmative and negative sentences. In Proceedings of the 27th Annual Conference of the Cognitive Science Society (pp. 1114-1119). Mahwah, NJ: Lawrence Erlbaum.

Kintsch, W. (1988). The use of knowledge in discourse processing: A construction-integration model. Psychological Review, 95, 163-182.

Koops van 't Jagt, R., Hoeks, J.C.J., Jansen, C.J.M., Winter, A.F. de, \& Reijneveld, S.A. (2015). Comprehensibility of health-related documents for older adults with different levels of health literacy: A systematic review. Journal of Health Communication, 21(2), 159-177.

Land, J.F.H. (2009). Zwakke lezers, sterke teksten? Effecten van tekst- en lezerskenmerken op het tekstbegrip en de tekstwaardering van vmbo-leerlingen. Stichting Lezen Reeks 13. Delft: Eburon.

Land, J.F.H., Sanders, T.J.M., \& Bergh, H.H. van den (2008). Effectieve tekststructuur voor het vmbo: Een corpus-analytisch en experimenteel onderzoek naar tekstbegrip en tekstwaardering van vmbo-leerlingen voor studieteksten. Pedagogische Studiën, 85(2), 76-94.

Lentz, L.R., \& Pander Maat, H.L.W. (2010). Een betere bijsluiter. Tijdschrift voor Taalbeheersing, 32 (2), 128-151.

Lorch, J.R.F., Lorch, E.P., \& Klusewitz, M.A. (1995). Effects of typographical cues on reading and recall of text. Contemporary Educational Psychology, 20(1), 51-64.

Lüdtke, J., \& Kaup, B. (2006). Context effects when reading negative and affirmative sentences. In Proceedings of the 28th Annual Conference of the Cognitive Science Society (pp. 1735-1740). Mahwah, NJ: Lawrence Erlbaum.

Margolin, S.J. (2013). Can bold typeface improve readers' comprehension and metacomprehension of negation? Reading Psychology, 34(1), 85-99.

Margolin, S.J., \& Abrams, L. (2009). Not may not be too difficult: The effects of negation on older adults' sentence comprehension. Educational Gerontology, 35(4), 308-322.

McNamara, D.S., Kintsch, E., Songer, N.B., \& Kintsch, W. (1996). Are good texts always better? Text coherence, background knowledge, and levels of understanding in learning from text. Cognition and Instruction, 14, 1-43.

Meuffels, B. \& Bergh, H. van den (2005). De ene tekst is de andere niet. The language-as-a-fixedeffect fallacy revisited: Methodologische implicaties. Tïdschrift voor Taalbeheersing, 27, 106125 .

O'Keefe, D.J. (2002). Persuasion: Theory and research (2nd ed.). Thousand Oaks, CA: Sage.

Open Science Collaboration (2015). Estimating the reproducibility of psychological science. Science, $349(6251)$, aac4716.

O'Reilly, T., \& McNamara, D.S. (2007). Reversing the reverse cohesion effect: Good texts can be better for strategic, high-knowledge readers. Discourse Processes, 43(2), 121-152.

Pander Maat, H., \& Lentz, L. (2011). Een Kennisbank over Begrijpelijke Taal. Tijdschrift voor Taalbeheersing, 33(3), 208-232.

Paradis, C., \& Willners, C. (2006). Antonymy and negation: The boundedness hypothesis. Journal of Pragmatics, 38(7), 1051-1080.

Rigney, D. (2010). Matthew Effect: How advantage begets further advantage. New York: Columbia University Press.

Sanders, T., \& Jansen, C. (2011). Begrijpelijke taal - fundamenten en toepassingen van effectieve communicatie. Tijdschrift voor Taalbeheersing, 33(3), 201-207.

Sanders, T.J.M., \& Noordman, L.G.M. (2000). The role of coherence relations and their linguistic markers in text processing. Discourse Processes, 29(1), 37-60.

Shapiro, A., \& Milkes, A. (2004). Skilled readers make better use of anaphora: A study of the repeated-name penalty on text comprehension. Electronic Journal of Research in Educational Psychology, 2(2), 161-180. 
Sherman, M.A. (1973). Bound to be easier? The negative prefix and sentence comprehension. Journal of Verbal Learning and Verbal Behavior, 12(1), 76-84.

Sherman, M.A. (1976). Adjectival negation and the comprehension of multiply negated sentences. Journal of Verbal Learning and Verbal Behavior, 15(2), 143-157.

Silfhout, G. van (2014). Leuk om te lezen of makkelijk te begrijpen? Optimaal begrijpelijke teksten voor het voortgezet onderwijs. Stichting Lezen Reeks 23. Delft: Eburon.

Silfhout, G. van, Evers-Vermeul, J., Mak, W.M., \& Sanders, T.J.M. (2014). Connectives and lay-out as processing signals: How textual features affect students' on-line processing and text representation. Journal of Educational Psychology, 106(4), 1036-1048.

Silfhout, G. van, Evers-Vermeul, J., \& Sanders, T.J.M. (2013). Omdat het schrijven van studieteksten en toetsvragen niet eenvoudig is: Effectieve opbouw en presentatie van studiematerialen. De Cascade: Tijdschrift voor Onderwijs, Onderzoek \& Ontwikkeling, 10(1), 17-20.

Silfhout, G. van, Evers-Vermeul, J., \& Sanders, T. (2015). Connectives as processing signals: How students benefit in processing narrative and expository texts. Discourse Processes, 52(1), 4776 .

Sticht, T. (1985). Understanding readers and their uses of texts. In T.M. Duffy \& R. Waller (Red.), Designing usable texts (pp. 315-339). London: Academic Press.

Stichting Lezen en Schrijven (2017). Feiten \& cijfers geletterdheid 2016: Overzicht van de gevolgen van laaggeletterdheid en de opbrengsten van investeringen voor samenleving en individu. Den Haag: Stichting Lezen en Schrijven. Geraadpleegd op 28 februari 2017: http://www.lezenenschrijven.nl/uploads/editor/201602_SLS_Litstudie_FeitenCijfers_web.pdf.

Wilson, E.A., \& Park, D.C. (2008). A case for clarity in the writing of health statements. Patient Education and Counseling, 72(2), 330-335.

\section{Over de auteurs}

Jacqueline Evers-Vermeul werkt als docent-onderzoeker bij het Departement Talen, Literatuur en Communicatie aan de Universiteit Utrecht. Zij doet onderzoek naar taal- en geletterdheidontwikkeling en de rol die teksten daarin spelen. Correspondentieadres: Utrechts Instituut voor Linguïstiek OTS, Universiteit Utrecht, Trans 10, 3512 JK Utrecht.

E-mailadres: j.evers@uu.nl.

Carla van Rooijen behaalde haar master Communicatie \& Organisatie aan de Universiteit Utrecht. Zij werkt momenteel als communicatieonderzoeker bij de Sociale Verzekeringsbank.

E-mailadres: c.vanrooijenı2@gmail.com. 